\title{
Juvenile hominoid cranium from the terminal Miocene of Yunnan, China
}

\author{
JI XuePing ${ }^{1,2}$, JABLONSKI Nina $\mathrm{G}^{3}$, SU Denise $\mathrm{F}^{4}$, DENG ChengLong ${ }^{5}$, \\ FLYNN Lawrence $\mathbf{J}^{6}$, YOU YouShan ${ }^{7} \&$ KELLEY Jay ${ }^{8 *}$ \\ ${ }^{1}$ Department of Paleoanthropology, Yunnan Institute of Cultural Relics and Archaeology, Kunming 650118, China; \\ ${ }^{2}$ Yunnan Key Laboratory for Paleobiology, Yunnan University, Kunming 650091, China; \\ ${ }^{3}$ Department of Anthropology, The Pennsylvania State University, University Park, PA 16802, USA; \\ ${ }^{4}$ Department of Paleobotany and Paleoecology, Cleveland Museum of Natural History, Cleveland, OH 44106, USA; \\ ${ }^{5}$ State Key Laboratory of Lithospheric Evolution, Institute of Geology and Geophysics, Chinese Academy of Sciences, Beijing 100029, China; \\ ${ }^{6}$ Peabody Museum of Archaeology and Ethnology, Harvard University, Cambridge, MA 02138, USA; \\ ${ }^{7}$ Zhaotong Institute of Cultural Relics, Zhaotong 657000, China; \\ ${ }^{8}$ Institute of Human Origins and School of Human Evolution and Social Change, Arizona State University, Tempe, AZ 85287, USA
}

Received May 28, 2013; accepted July 8, 2013; published online August 7, 2013

Fossil apes are known from several late Miocene localities in Yunnan Province, southwestern China, principally from Shihuiba (Lufeng) and the Yuanmou Basin, and represent three species of Lufengpithecus. They mostly comprise large samples of isolated teeth, but there are also several partial or complete adult crania from Shihuiba and a single juvenile cranium from Yuanmou. Here we describe a new, relatively complete and largely undistorted juvenile cranium from the terminal Miocene locality of Shuitangba, also in Yunnan. It is only the second ape juvenile cranium recovered from the Miocene of Eurasia and it is provisionally assigned to the species present at Shihuiba, Lufengpithecus lufengensis. Lufengpithecus has most often been linked to the extant orangutan, Pongo pygmaeus, but recent studies of the crania from Shihuiba and Yuanmou have demonstrated that this is unlikely. The new cranium reinforces the view that Lufengpithecus represents a distinct, late surviving lineage of large apes in the late Miocene of East Asia that does not appear to be closely affiliated with any extant ape lineage. It substantially increases knowledge of cranial morphology in Lufengpithecus and demonstrates that species of this genus represent a morphologically diverse radiation of apes, which is consistent with the dynamic tectonic and biotic milieu of southwestern China in the late Miocene.

Miocene hominoid, Lufengpithecus, cranial morphology, hominoid phylogeny, fossil primates

Citation: Ji X P, Jablonski N G, Su D F, et al. Juvenile hominoid cranium from the terminal Miocene of Yunnan, China. Chin Sci Bull, 2013, 58: 3771-3779, doi: $10.1007 / \mathrm{s} 11434-013-6021-\mathrm{x}$

Fossil ape remains have been recovered from several late Miocene localities in Yunnan Province, southwestern China, and have been assigned to three species of the genus Lufengpithecus: L. keiyuanensis from near Kaiyuan in the Xiaolongtan Basin ( 10-11 Ma) [1-3], L. hudienensis from multiple sites in the Yuanmou Basin (7.1-8.2 Ma) [4-6], and $L$. lufengensis from Shihuiba in the Lufeng Basin (6.2-6.9 Ma) [6-8]. Partial to nearly complete crania have been recovered

*Corresponding author (email: jkelley.iho@asu.edu) for the latter two species. L. lufengensis is represented by several crania, but, with the exception of a juvenile frontal, all are crushed and badly deformed [9-12] although an attempt has been made to reconstruct one of them [12]. The single cranium of L. hudienensis is from a young juvenile and is minimally distorted [13-15]. Here we report the discovery of a new, relatively complete juvenile cranium of the fossil hominoid Lufengpithecus. The new cranium, ZT 299, although partly broken during recovery, shows almost no distortion and provides valuable information about the 
morphology of Lufengpithecus.

\section{Site biochronology and geochronology}

ZT 299 is from the locality of Shuitangba (Figure 1), an open-pit lignite mine located in the Zhaotong Basin in northeastern Yunnan Province. Previous estimates of the age of the vertebrate fossils from the Zhaotong Basin ranged from Pliocene to early Pleistocene [16], but the results of our biochronological and geochronological investigations instead indicate a terminal Miocene age.

The recovered fauna from Shuitangba belongs to the Asian Baodean Stage/Age, a standard terrestrial biochron for the late Miocene bracketed by dates in the time range of
7.2 to $5.3 \mathrm{Ma}$ [17]. The time-constrained rodent genera $\mathrm{Si}$ nocastor (a beaver), Kowalskia (a hamster), and Pliopetaurista (a flying squirrel) all indicate an age no older than the latest Miocene and no younger than the early Pliocene. The hare Alilepus appears abruptly in the late Miocene of China as an immigrant from North America and is likely restricted to Baodean time. The bamboo rat Miorhizomys [18], a late Neogene predecessor of Pliocene Rhizomys, is similar to the species from the Siwaliks of Pakistan, which is well-dated and supports a late Miocene rather than Pliocene age. A late Miocene age for the Shuitangba fauna is also supported by the composition of the large mammal fauna, particularly proboscideans. There are at least two proboscidean species at Shuitangba, cf. Stegodon zhaotongensis and cf. Sinomastodon sp. Stegodon is a widespread member of late Baodean-

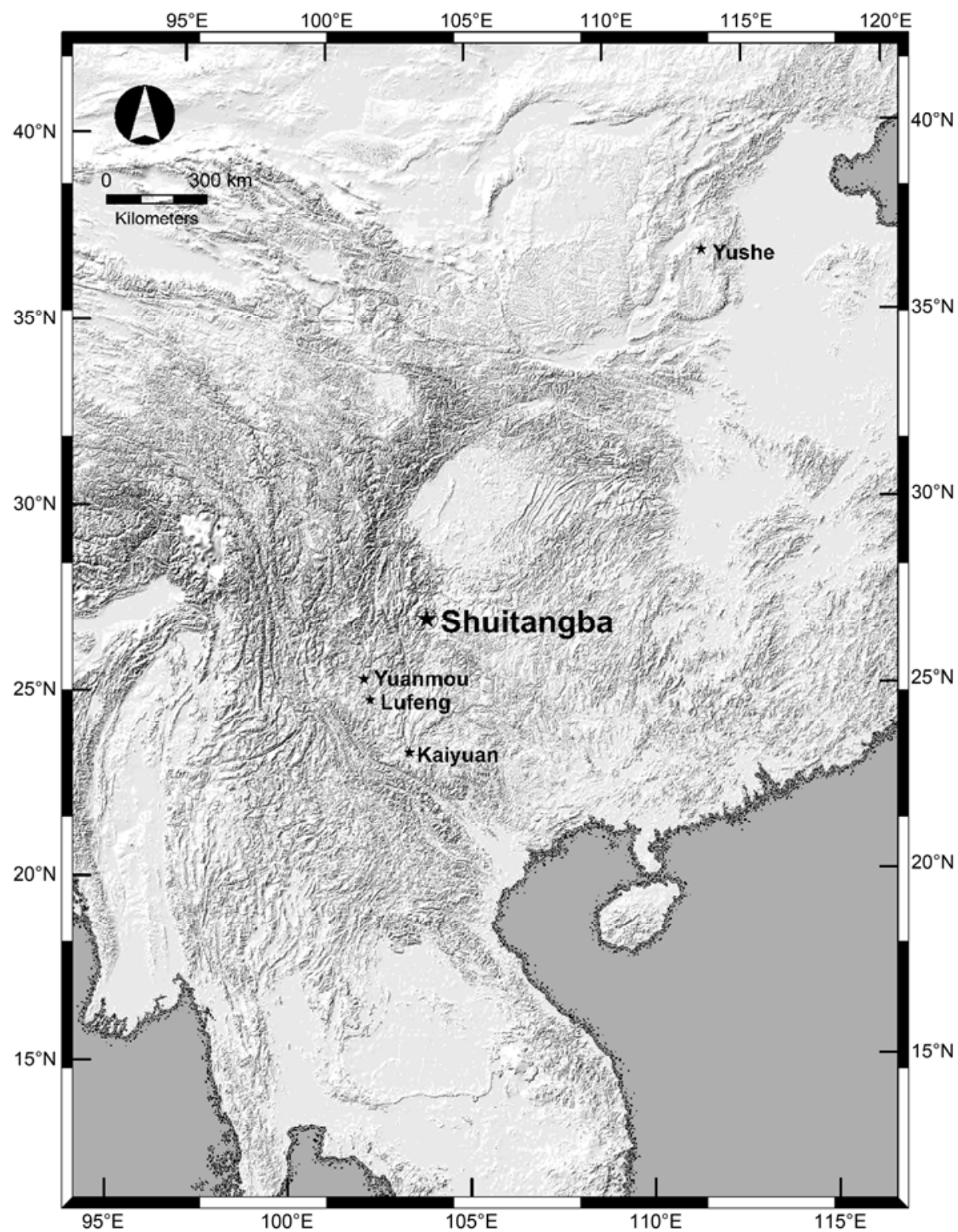

Figure 1 The principal late Miocene hominoid-bearing sites in Yunnan Province. Also shown is the location of the latest Miocene through Pliocene Yushe reference sequence in Shanxi Province. 
age assemblages and Sinomastodon is known from the MioPliocene boundary to the late Pliocene elsewhere in China [19]. Stegodon zhaotongensis is a primitive stegodont recorded from latest Miocene-early Pliocene sediments in China [20]. The mammalian biochronology is consistent with the presence of late Miocene fossil pollens [21].

We also dated the site paleomagnetically. Because of the thinness of the sedimentary section at Shuitangba, a bore- hole was drilled in a thicker part of the section several hundred meters away. Correlation between the fossil and borehole sites was by means of a distinct lignite-peaty clay-lignite triplet (Figure 2). The key fossils occur in the upper half of the peaty clay. Correlation to the geomagnetic polarity timescale (GPTS), aided by the biochronological constraints noted above, reveals that the top half of the peaty clay captures the base of subchron C3An.1n, the top of C3An.2n,

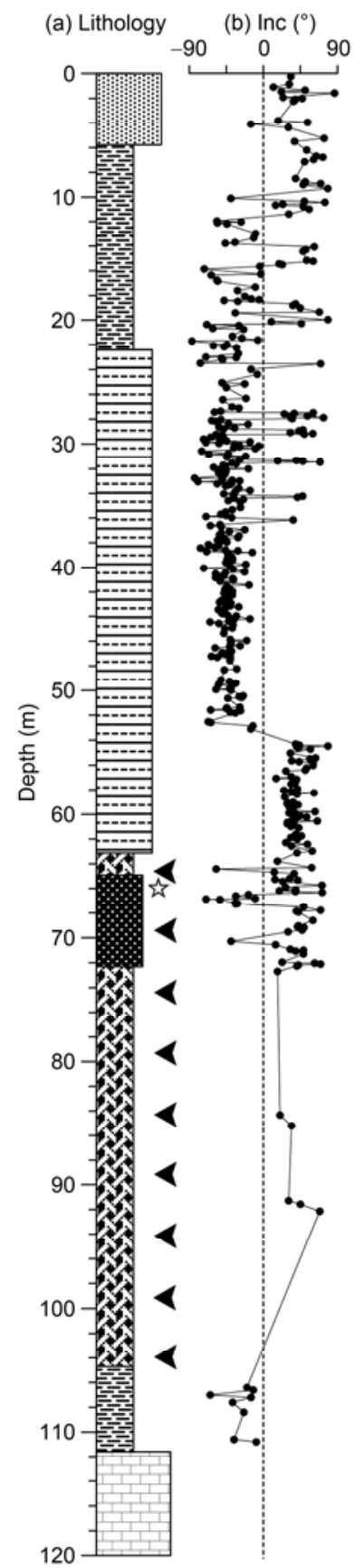

(c) Polarity

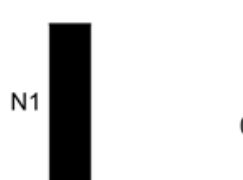

(d) GPTS

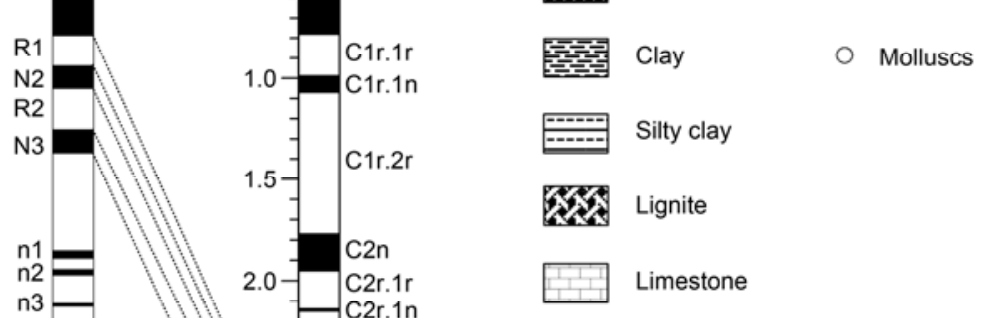

88 Conglomerate

(e) Polarity (f) VGP lat. $\left({ }^{\circ}\right)(g)$ Lithology
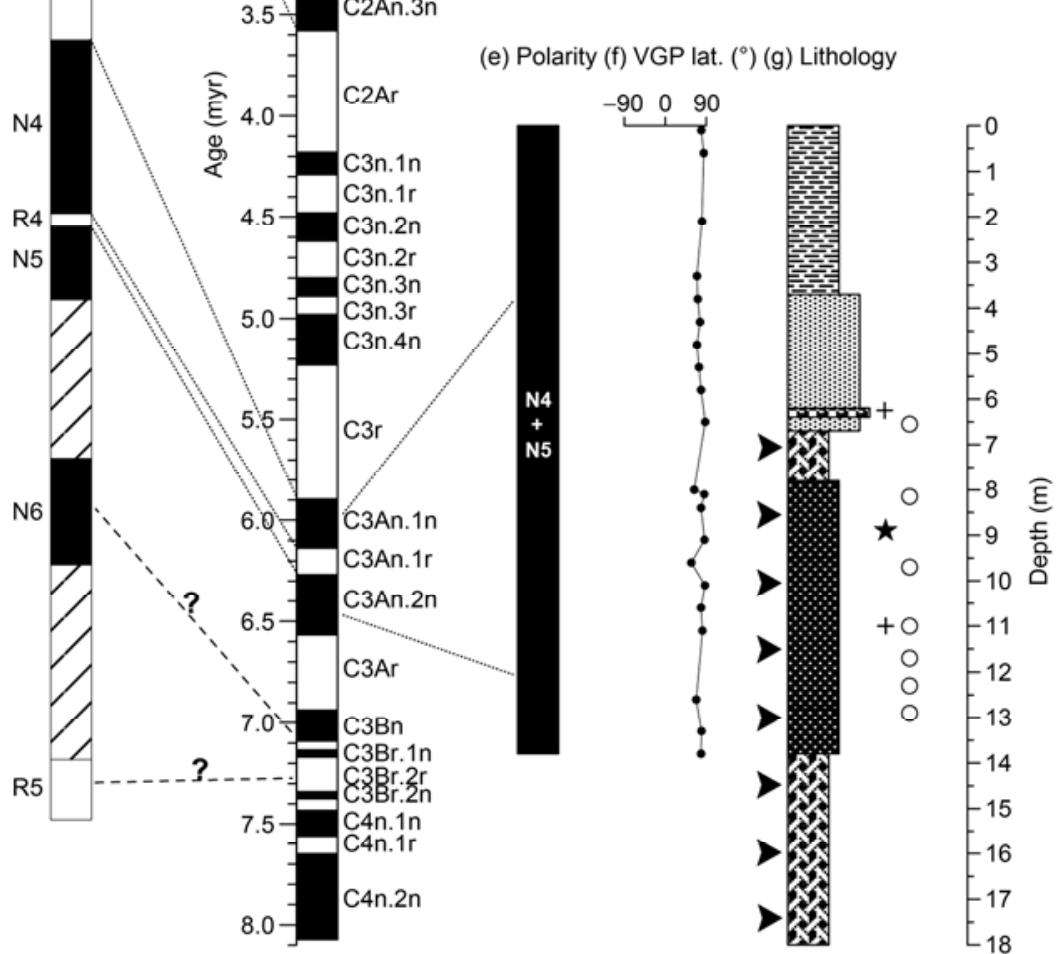

Figure 2 Lithostratigraphy and magnetostratigraphy of the borehole core (a)-(c) and the Shuitangba site (e)-(g). (a) and (g) lithology; (b) inclination; (c) and (e) magnetic polarity zonation; (d) geomagnetic polarity timescale (GPTS); (f) VGP latitudes. The hatched areas in (c) indicate missing data due to breakup of the sediment in those intervals. The hominoid-bearing layer at the site, indicated by the solid star in (g), corresponds to the layer indicated by the empty star in the core (a) and plots at the base of subchron C3An.1n. The stratigraphic correlation between the core and the site is based on the lignite-peaty clay-lignite triplet (solid arrows) from which the primate fossils were recovered. 
and the short intervening reversed C3An.1r. Interpolation of the hominoid level places it near the C3An.1r-C3An. 1n transition, which is estimated at $6.13 \mathrm{Ma}$ or $6.24 \mathrm{Ma}$ based on the two most widely used geomagnetic timescales [22,23], making ZT 299 slightly younger than the youngest L. lufengensis material from Shihuiba.

We note, though, that since C3An.1r is missing in the short section from the fossil site (column [e] in Figure 2), it is possible that the normal polarity zone at the site represents only C3An.1n or C3An.2n. Thus, the layer from which the cranium was recovered is conceivably as young as 6.0 or as old as $6.5 \mathrm{Ma}$. However, given the proximity of the borehole to the fossil site and the nearly equal thickness of the peaty clay in the two sections, it is highly likely that the boundary between the peaty clay and the upper lignite in the two sections is contemporaneous, essentially an isochron. In that case, the normal zone at the fossil site does capture the base of C3An.1n and the short reversed polarity zone C3An.1r (only $1 \mathrm{~m}$ thick in the borehole) is simply not recorded, perhaps due to proximity of the site to the sub-basin margin while the borehole is closer to the center.

\section{Description of ZT 299}

ZT 299 is a partial cranium of a young juvenile and preserves most of the facial skeleton, most of the frontal squama, and, internally, the floor of the anterior cranial fossa, the post-orbital septa, and much of the sphenoid save for the vertical plates of the greater wings (Figures 3-5; Table 1). There is a well preserved brain endocast corresponding to the preserved portion of the neurocranium. Of the permanent dentition, only the first molars had erupted. Judging by the amount of wear, they had been in occlusion for some time. The remaining permanent teeth are preserved in their crypts except for the $\mathrm{M}^{3} \mathrm{~s}$, which had perhaps begun to form but are not obviously discernible in radiographic images, and the right $\mathrm{I}^{2}$, which was not preserved. The left $\mathrm{dp}^{4}$ is the only deciduous tooth preserved. The cranium was partly broken during initial exposure but with minimal damage to individual pieces. It has been possible to accurately reposition all portions except for a section comprising the nasoalveolar and left malar/zygomatic regions, although this section is intact (Figure 4). The cranium shows no deformation beyond a slight anterior and medial displacement of the left frontal. Breakage also exposed the incisors, canines and left $\mathrm{P}^{3}$ within their crypts, permitting their morphological characterization and measurement (Figures 4 and 5; Table 1). The incomplete canine crowns are large with the beginnings of a deep mesial groove and are clearly male.

ZT 299 is characterized by prominent, robust and arching supraorbital costae extending from the zygomatico-frontal suture to near the midline where they blend into the flattened glabellar area. The frontal squama extends nearly vertically from the supraorbital costae and gradually angles more posteriorly to the coronal suture, resulting in the facial skeleton being positioned relatively low with respect to the neurocranium. CT imaging reveals the presence of an incipient, ethmoidally-derived frontal sinus (Figure 6). The orbits are substantially broader than tall, much more so than in any of the extant great ape juveniles in our comparative sample (height/breadth index, ZT 299: 0.86; great ape range:

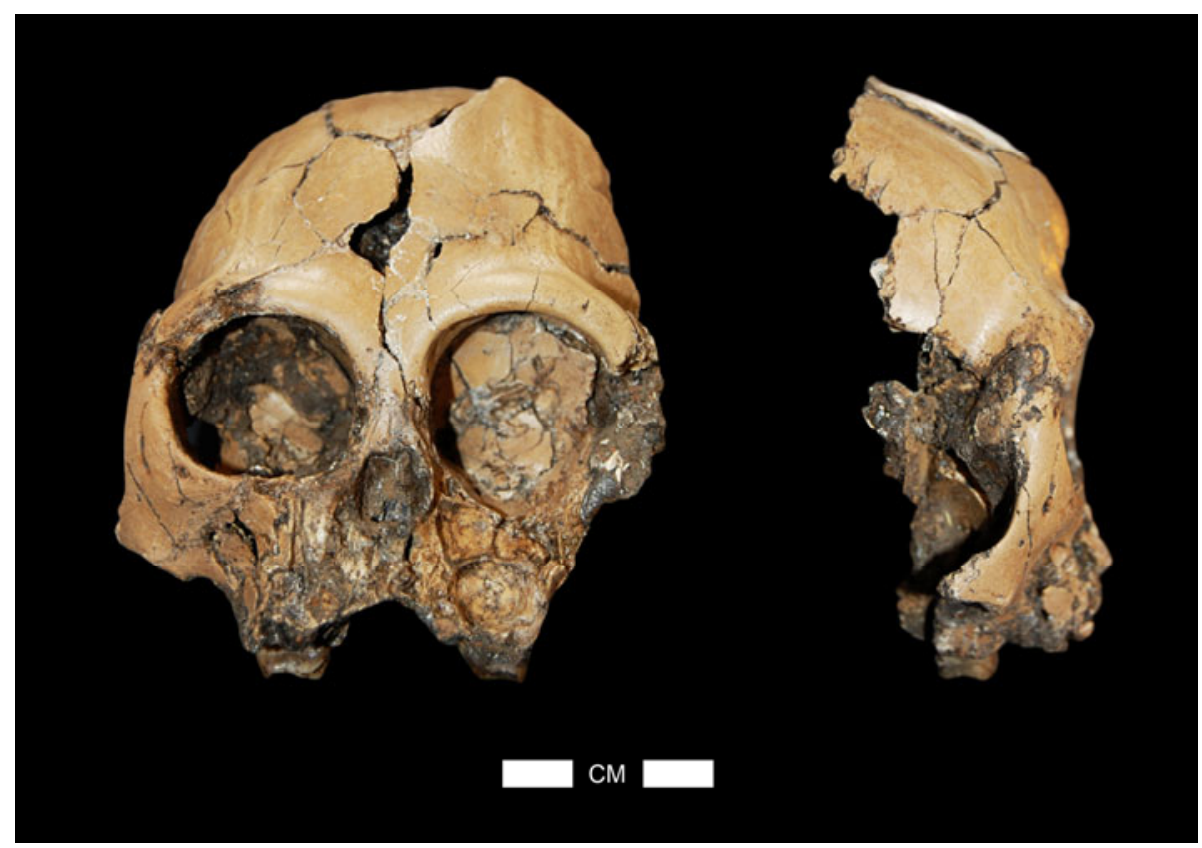

Figure 3 ZT 299 in frontal view (left) and lateral view (right). The left malar and most of the nasoalveolar region are preserved as a separate fragment, shown in Figure 4. Separation of this fragment during recovery of the specimen exposed the crypts of the permanent canine and the $\mathrm{P}^{3}$ on the left side. Note that the actual contour of the frontal squama in lateral view is somewhat distorted by the displaced bone of the left portion of the frontal. 


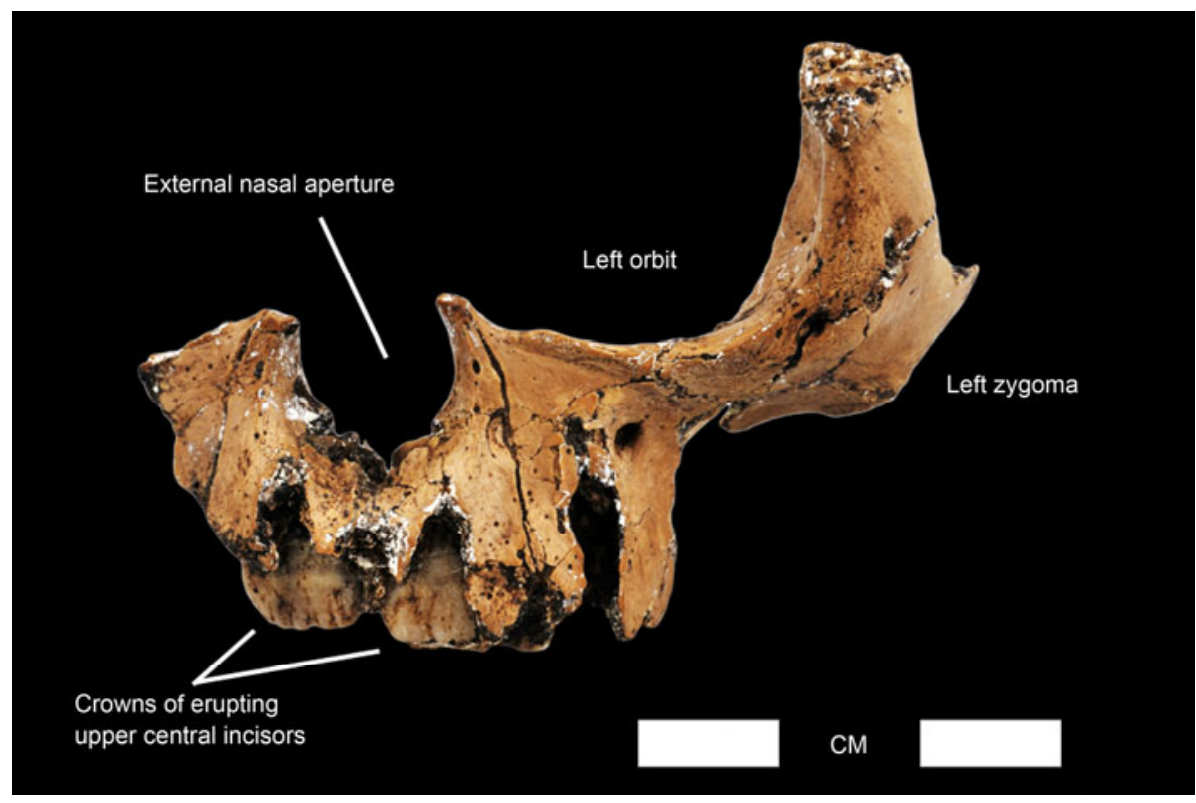

Figure 4 The nasoalveolar and left malar regions of ZT 299. The central incisors had begun to erupt but had not yet emerged beyond the alveolar margin. This fragment can be approximated to its original position but it cannot be reattached to the rest of the cranium because of damage along the cleavage plane between the two portions.

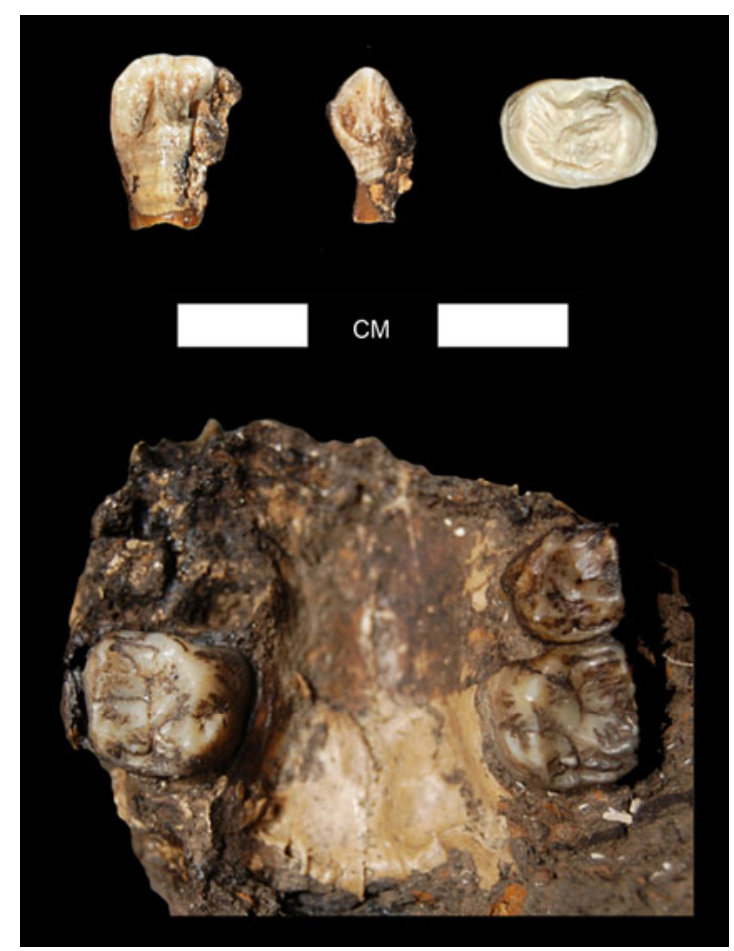

Figure 5 The partial dentition of ZT 299. The left and right $\mathrm{M}^{1} \mathrm{~s}$ and $\mathrm{dP}^{4}$ (bottom) are in situ. The unerupted right $\mathrm{I}^{1}$ (top left) and left $\mathrm{I}^{2}$ (top middle) are exposed in their crypts while the left $\mathrm{P}^{3}$ (top right) was dislodged from its crypt during excavation.

1.00-1.34), and are separated by a moderately wide interorbital septum. The lateral orbital pillar is robust, faces anterolaterally and broadens inferiorly. The nasals are flat and non-projecting, contributing to an orbital plane that closely
Table 1 Dental and cranial measurements of ZT $299^{\text {a) }}(\mathrm{mm})$

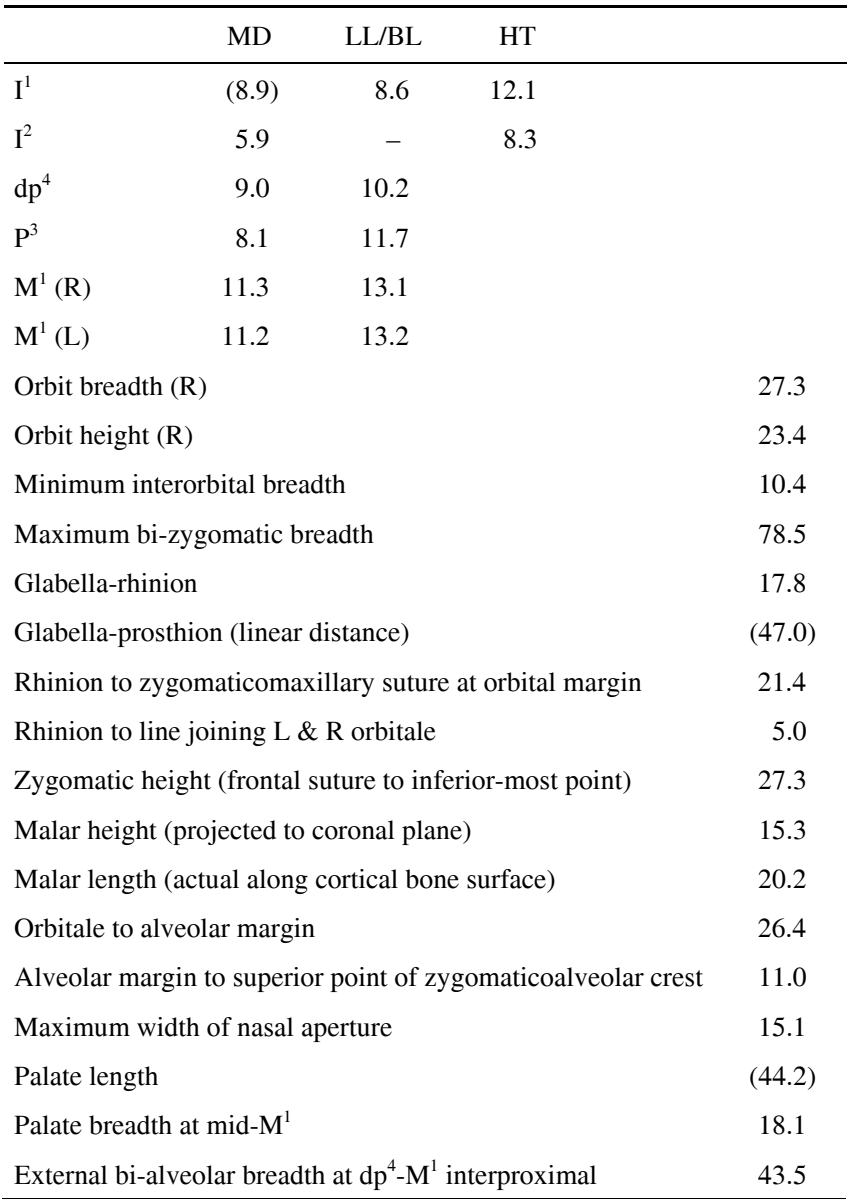

a) MD, mesiodistal; LL, Labiolingual; BL, buccolingual; HT, height; L, left; R, right. Parentheses indicate estimates. 
approximates the coronal plane. The nasal aperture is roughly pear-shaped, being widest near the base. The malar region is strongly posteriorly inclined from the infraorbital margin and thus appears vertically shortened in frontal view and "backswept" into the zygomatic root in lateral view. As a consequence of this orientation, and in conjunction with the prominent supraorbital costae, the orbital margins project forward of the rest of the upper and mid-face. Although the nasoalveolar/left zygomatic fragment cannot be reattached to the remainder of the cranium, it can be approximated to its correct position sufficiently closely to show that the posterior pole of the nasoalveolar clivus is positioned well above the level of the nasal floor and that the nasoalveolar clivus is short and steeply angled, resulting in little nasoalveolar prognathism.

Based on partly estimated measurements (Table 1), the $\mathrm{I}^{1}$ crown appears to be relatively narrow mesiodistally and thick labiolingually, and bears a prominent, sharply-defined lingual pillar. The $\mathrm{I}^{2}$ has a nearly symmetrical crown profile with mesial and distal incisal edges nearly equal in length and slope. The $\mathrm{P}^{3}$ has a relatively low but distally extended protocone that merges into a prominent distal marginal ridge delimiting an expansive occlusal basin. The $\mathrm{dP}^{4}$ has a large hypocone and, although worn, shows vestiges of enamel crenulations. The $\mathrm{M}^{1} \mathrm{~s}$ are relatively broad buccolingually and have marginalized cusp apices, resulting in expansive occlusal basins. The buccal cusps are positioned only slightly more mesially than the lingual cusps and there is a distinct accessory cusp on the preprotocrista. The occlusal enamel is heavily but coarsely wrinkled.

\section{Comparative morphology}

ZT 299 shares the distinctive pattern of dental morphology

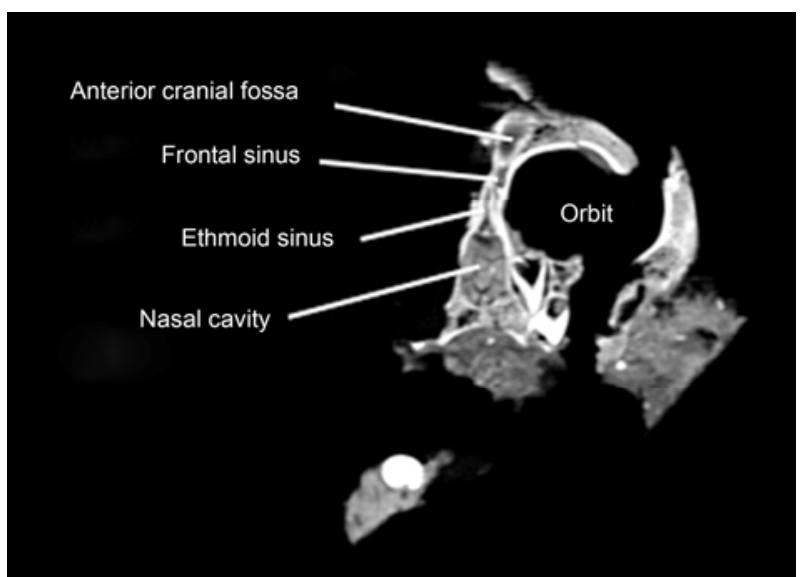

Figure 6 Coronal CT section of ZT 299 showing the incipient development of the frontal sinus from the ethmoid sinus. CT scanning took place prior to the right zygomatic being reattached to the main portion of the cranium. The detached element in the lower central portion of the image is matrix. expressed by the other two well represented species of Lufengpithecus, L. lufengensis and L. hudienensis [8,24], including narrow upper central incisors with pronounced, high-relief lingual pillars and relatively very large molars with relatively flat occlusal surfaces, peripherally positioned cusps delimiting expansive occlusal basins, and coarsely but densely crenulated enamel. This combination of features is not expressed by any other hominoid genus. Only a few maxillary teeth of Khoratpithecus from the late Miocene of Thailand and Myanmar have been recovered [25,26]. While the molars (three $\mathrm{M}^{2} \mathrm{~s}$ ) are similar to those of ZT 299 in having broad occlusal basins and coarsely wrinkled enamel, they are more elongate (length/breadth index: 0.94-0.98; 0.85 and 0.86 for the two ZT $299 \mathrm{M}^{1} \mathrm{~s}$ ), and have more mesially positioned buccal cusps in relation to the lingual cusps. Khoratpithecus also has different incisor morphology, with an $\mathrm{I}^{1}$ that is relatively broad bearing a short and broad basal lingual tubercle.

Among species of Lufengpithecus, L. keiyuanensis is known from very few specimens. The only maxillary teeth are those in a crushed and partial female maxilla, YVO 720 , bearing the left $1^{2}-\mathrm{M}^{3}$ and the right $\mathrm{C}-\mathrm{M}^{2}$ [2]. The $\mathrm{I}^{2}$ is asymmetrical in outline, with the distal incisal edge being longer and more steeply sloped than the mesial. The $\mathrm{P}^{3}$ has a very small protocone in comparison to the paracone, representing only about one-third of the occlusal surface of the tooth. This results in an occlusal outline that is roughly triangular, in contrast to the ovoid outline of the ZT $299 \mathrm{P}^{3}$. The internal faces of the cusps slope steeply down to the central fissure resulting in a constricted occlusal surface, unlike the very expansive surface in ZT 299. The mesial and distal marginal ridges are not strongly developed. The $\mathrm{M}^{1} \mathrm{~s}$ are relatively long mesiodistally (length/breadth $=0.95$, average of left and right $\mathrm{M}^{1} \mathrm{~s}$ [2]) and the buccal cusps are positioned substantially mesially to the lingual cusps, especially the metacone so that its mesiodistal position is nearly midway between the protocone and hypocone. The buccal and lingual cusps are only slightly offset in this fashion in the ZT $299 \mathrm{M}^{1} \mathrm{~s}$. The $\mathrm{M}^{1}$ paracone is relatively much smaller in YVO 720 and the crista obliqua is deeply bisected by a fissure, in contrast to the essentially continuous crista obliqua in ZT 299.

The juvenile cranium of $L$. hudienensis from Yuanmou (YV0999) is only slightly younger developmentally than ZT 299 , with the $M^{1}$ s having erupted but showing no evidence that they were yet in occlusion [15]. Thus, any morphological differences with ZT 299 are unlikely to be due to ontogenetic changes. The greatest differences between ZT 299 and YV0999 are found in the orbital region (Figure 7). In contrast to ZT 299, YV0999 lacks supraorbital costae and has a slightly inflated glabellar region. The orbits are also sub-round and as tall as they are broad [15]. However, while the two specimens differ substantially in an index of orbital height/width, they both fall within the absolute range of Pongo, which comprises the largest sample $(n=17)$ among 


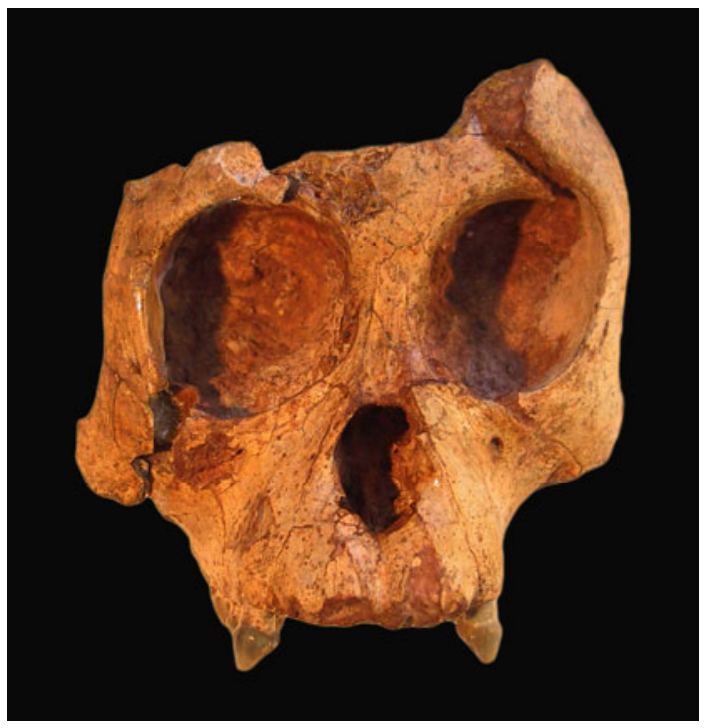

Figure 7 Juvenile cranium of Lufengpithecus hudienensis (YV0999). In contrast to ZT 299, the orbit is sub-round in shape and slightly taller than wide, the frontal process of the zygomatic (lateral orbital pillar) does not broaden appreciably before merging with the temporal process of the zygomatic arch, and there is no development of supraorbital costae. The latter feature is most evident in the left supraorbital region, where, although there is breakage and overlap, there is no distortion of the supraorbital area where it begins to transition into the frontal squama.

our juvenile great ape comparative samples (ZT 299: 0.86; YV0999: 1.01; Pongo absolute range [maximum minus minimum]: 0.28). In YV0999, the plane of the orbital margin is somewhat oblique to the coronal plane so that the orbital plane angles slightly posteriorly from the midline and the orbits consequently face somewhat antero-laterally rather than directly anteriorly. In ZT 299 on the other hand, the orbital plane closely approximates the coronal plane and the orbits face almost directly forward. The difference between these two individuals in this feature is notably greater than the extremes in each of the extant great ape juvenile samples. The lateral orbital pillar in YV0999 has a more or less constant width, broadening only as the zygomatic frontal process begins to merge with the temporal process, in contrast to the inferior broadening in ZT 299. In the mid-facial region, the inferior nasals project anteriorly in YV0999, whereas they lie within the plane of the orbit in ZT 299. Finally, in contrast to the strongly posteriorly inclined malar region with respect to the alveolar margin (as defined in the $\mathrm{M}^{1}-\mathrm{dP}^{4}$ region) in ZT $299\left(60^{\circ}\right.$ and near the bottom of the extant great ape juvenile range), that of YV0999 is more nearly vertical $\left(83^{\circ}\right.$ and in the upper part of the great ape range).

Dentally, ZT 299 can be compared to the much larger sample of $L$. hudienensis. $\mathrm{I}^{2} \mathrm{~s}$ of the latter are strongly bilaterally asymmetrical, with a short, shallowly inclined mesial incisal edge and a long steeply inclined distal edge, in contrast to the nearly symmetrical outline of the ZT $299 \mathrm{I}^{2}$. $L$. hudienensis $\mathrm{P}^{3} \mathrm{~s}$ lack the expanded protocone seen on the ZT $299 \mathrm{P}^{3} \mathrm{~s}$ and have more closely approximated cusp tips, a combination that results in a much less expansive occlusal basin.
Comparisons between ZT 299 and the crania of L. lufengensis from Shihuiba are more difficult because all but one of the latter are from adults and crushed, and the one juvenile, PA 828, only preserves the frontal. PA 828 is strikingly similar to the frontal of ZT 299, with pronounced supraorbital costae that converge medially toward what appears to have been a more or less flattened glabellar area, although this area is incompletely preserved in PA 828 [12]. While the interorbital area is not preserved, the contours of the preserved parts of the converging orbital margins indicate that the interorbital region would have been moderately relatively wide as in ZT 299.

One of the adult crania of L. lufengensis, PA 644, has been reconstructed [12] and can serve as a basis of comparison for other aspects of cranial morphology. However, any conclusions drawn from this comparison must be viewed with caution given both the different developmental stages of ZT 299 and PA 644, as well as the difficulties involved in reconstructing a cranium as badly crushed as PA 644. PA 644 is reconstructed as having robust supraorbital costae, a flattened frontal squama that angles more posteriorly than vertically from the supraorbital area, orbits that are subround but somewhat wider than tall, and a lateral orbital pillar that faces anteriorly and that broadens markedly inferiorly. The glabellar area is deeply depressed between the supraorbital costae, with the depression extending as a Ushaped trough through the extremely wide interorbital region all the way to rhinion. The malar region is moderately deep and vertically oriented. The degree of nasoalveolar prognathism is described as weak [12], but the published photographs reveal that it is actually quite pronounced (Figures $2.6 \& 2.7$ in [12]).

While many aspects of this reconstruction, such as glabellar and interorbital morphology plus the shape and orientation of the frontal squama, appear to be due to the inability to fully correct plastic deformation, others, such as the supraorbital costae, general orbital shape, inferior widening of the lateral orbital pillar, malar orientation, and some degree of nasoalveolar prognathism, appear to approximate original morphology. Of the latter, malar orientation and nasoalveolar prognathism undergo generally predictable changes during ontogeny in extant great apes [27], so that differences between ZT 299 and PA 644 in these features might to a greater or lesser degree reflect the different developmental stages of the two crania.

Comparisons with dental samples of Lufengpithecus lufengensis reveal that the teeth of ZT 299 are broadly similar to those of L. lufengensis and fall within the ranges of variation of that species both metrically [28] and in terms of discrete features $[8,12]$.

\section{Discussion}

ZT 299 is only the second relatively complete cranium of a 
young juvenile among Miocene hominoids, both belonging to species of Lufengpithecus. As such, it affords the opportunity to explore cranial ontogeny in Lufengpithecus in comparison to extant great apes, although this is made difficult because of the poor condition of the adult crania from Shihuiba. However, its juvenile status also complicates taxonomic assessment. As detailed above, ZT 299 is more similar to L. lufengensis than to either L. keiyuanensis or L. hudienensis, dentally and, in the case of the latter, cranially as well. Based on the noted differences between ZT 299 and the reconstructed adult cranium of L. lufengensis, PA644, it is possible that ZT 299 represents a new species of Lufengpithecus. This notion is at least lent plausibility by the primate faunas as a whole from the different hominoid sites, with no species in common among them and fundamental differences at the supra-specific level (Table 2). However, given the different developmental stages of the crania from Shuitangba and Shihuiba, limited samples, and uncertainty concerning certain aspects of the reconstruction of PA644, naming a new species currently cannot be justified. In light of the similarity between ZT 299 and PA828, the juvenile frontal from Shihuiba, and the lack of dental differences between ZT 299 and the samples from Shihuiba, we instead assign ZT 299 to Lufengpithecus cf. lufengensis.

Considering phylogeny, ZT 299 does not possess any of the key derived features that define the Pongo clade. These include supero-inferiorly elongate, ovoid orbits, a narrow interorbital septum, lack of a frontal sinus (incipiently developed in ZT 299), infraorbital foramina positioned well medial to the intersection of the zygomaticomaxillary sutures with the infraorbital margins, and a suite of features of the nasoalveolar region including an elongate and strongly biconvex nasoalveolar clivus resulting in marked prognathism, a smooth transition from the posterior pole of the

Table 2 Primates from late Miocene sites in Yunnan, China ${ }^{\text {a) }}$

\begin{tabular}{|c|c|c|c|c|}
\hline (Super)family & Species & Shuitangba & Shihuiba & Yuanmou \\
\hline Hominoidea & $\begin{array}{l}\text { Lufengpithecus } \\
\text { cf. lufengensis }\end{array}$ & + & & \\
\hline Hominoidea & $\begin{array}{l}\text { Lufengpithecus } \\
\text { lufengensis }\end{array}$ & & + & \\
\hline Hominoidea & $\begin{array}{l}\text { Lufengpithecus } \\
\text { hudienensis }\end{array}$ & & & + \\
\hline Pliopithecoidea & $\begin{array}{l}\text { Laccopithecus } \\
\text { robustus }\end{array}$ & & + & \\
\hline Sivaladapidae & $\begin{array}{l}\text { Indraloris } \\
\text { progressus }\end{array}$ & & & + \\
\hline Sivaladapidae & $\begin{array}{c}\text { Sinoadapis } \\
\text { parvulus }\end{array}$ & & & + \\
\hline Sivaladapidae & $\begin{array}{l}\text { Sinoadapis } \\
\text { carnosus }\end{array}$ & & + & \\
\hline Sivaladapidae & $\begin{array}{l}\text { Sinoadapis } \\
\quad \text { shihuibaensis }\end{array}$ & & + & \\
\hline Hylobatidae? & $\begin{array}{l}\text { Yuanmoupithecus } \\
\text { xiaoyuan }\end{array}$ & & & + \\
\hline Cercopithecoidea & $\begin{array}{l}\text { Mesopithecus } \\
\text { cf. pentelicus }\end{array}$ & + & & \\
\hline
\end{tabular}

a) Data for Shihuiba and Yuanmou [36,37]. clivus to the nasal floor and an extremely narrow incisive canal [29,30]. All of these features are clearly expressed in individuals of Pongo at the same stage of development as ZT 299 [15]. ZT 299 also lacks the few consensus derived cranial features of the extant African apes Pan and Gorilla, such as a continuous supraorbital torus offset from the frontal squama by a deep sulcus [30]. In most respects, ZT 299 conforms to expectations of the primitive hominid (extant great ape and human) morphotype, with an overlay of a few autapomorphic features, such as the exceptionally wide orbits resulting in a very wide mid-facial region.

Recent analyses of the crania of the other two well represented species of Lufengpithecus, L. lufengensis and $L$. hudienensis, also failed to find any clear craniofacial features supporting inclusion in the Pongo clade [12,15,31]. Species of Lufengpithecus appear, therefore, to represent a distinct clade of late Miocene East Asian hominoids not closely related to any of the extant great apes $[5,15,24]$ and that may have persisted into the Pleistocene [32].

Within Lufengpithecus, the striking differences in cranial morphology noted above between ZT 299 and the cranium of the slightly less mature juvenile of L. hudienensis, YV0999, are of particular interest. Such variation among related species from sites representing a restricted geographic area and a relatively short time interval suggests a degree of local endemism among apes in this region. This is compatible with current understanding of the topographic and environmental evolution of southwestern China during this time. In the latest Miocene and early Pliocene, the area south and southwest of the Sichuan Basin was subject to episodes of uplift and subsequent erosion related to the uplift of the eastern margin of the Tibetan Plateau [33,34]. These processes produced the complex topography of mountain ranges and intermontane basins characteristic of the region today. One apparent result of this was some degree of local faunal endemism throughout the region, exemplified by the striking dissimilarity noted above in the composition of the primate faunas as a whole from the three principal hominoid-bearing sites in Yunnan (Table 2). Of particular note in this regard is the presence of the cercopithecoid monkey Mesopithecus at Shuitangba, which represents the earliest occurrence of cercopithecoids in East Asia [35]. Beyond this, there are no primate species in common among the different sites and no uniformity in composition even at the level of superfamily. While some of this dissimilarity may be temporal in nature, such as the presence of the cercopithecoid at Shuitangba, the latest of these sites, much of it would appear to result from in situ divergence of isolated lineages. The diversity among primates at the different sites might have been one element of a larger pattern of local faunal endemism during the latest Miocene in the region [36].

We thank Mao Guodong for logistical support during excavation of the Shuitangba lignite mine; Wang Yi (Yuxi Museum) and Yang Xin (Zhaoyang 
Museum) for help in the field; Dr. Yohannes Haile-Selassie, Curator of Physical Anthropology, and Lyman Jellema, collections manager (Cleveland Museum of Natural History), Linda Gordon, collections manager (United States Natural History Museum) and Richard Kraft, Director (Zoologisches Staatssammlung, München) for allowing us to examine specimens housed at their institutions; Zhang Jianjun (Institute of Vertebrate Paleontology and Paleoanthropology) and You Pingping (Yunnan Institute of Cultural Relics and Archaeology) for help in preparing ZT 299; Tim Ryan and Yann Heuze (Penn State University) for the CT rendering; and the Yunnan Bureau of Geology and Mineral Resources Exploration for aid in drilling the borehole. This work was supported by the National Science Foundation (BCS 1035897, BCS 1227838 and BCS 0321893), Bryn Mawr College, the American Association of Physical Anthropologists the Yunnan Natural Science Foundation (2010CC010), the Zhaotong Government, the National Basic Research Program of China and the National Natural Science Foundation of China (2012CB821900 and 40925012). Figure 1 was prepared by George Chaplin and Figures 3-7 by Tess Wilson.

1 Woo J K. Dryopithecus teeth from Keiyuan, Yunnan Province. Vert Palasiat, 1957, 1: 25-32

2 Zhang X Y. New materials of Ramapithecus from Kaiyuan, Yunnan (in Chinese). Acta Anthrop Sin, 1987, 6: 81-86

3 Qiu Z X, Qiu Z D. Chronological sequence and subdivision of Chinese Neogene mammalian faunas. Palaeogeogr Palaeoclimatol Palaeoecol, 1995, 116: 41-70

4 Zhang X Y, Lin Y P, Jiang C, et al. A new species of Ramapithecus from Yuanmou, Yunnan (in Chinese). J. Yunnan Univ (Soc Sci), 1987, 3: 54-56

5 Qi G Q, Dong W, Zheng L, et al. Taxonomy, age and environment status of the Yuanmou hominoids. Chin Sci Bull, 2006, 51: 704-712

6 Yue L P, Zhang Y X. Paleomagnetic dating of Lufengpithecus hudienensis localities (in Chinese). In: Qi G Q, Dong W, eds. Lufengpithecus hudienensis Site. Beijing: Science Press, 2006. 245-255

7 Xu Q H, Lu Q W, Pan Y Y, et al. Fossil mandible of the Lufeng Ramapithecus (in Chinese). Kexue Tongbao, 1978, 9: 544-556

8 Wu R K, Xu Q H, Lu Q W. Morphological features of Ramapithecus and Sivapithecus and their phylogenetic relationships-Morphology and comparison of the teeth (in Chinese). Acta Anthropol Sin, 1985, 4: 197-204

9 Wu R K, Han D F, Xu Q H, et al. Ramapithecus skull found first time in the world (in Chinese). Kexue Tongbao, 1981, 26: 1018-1021

10 Wu R K, Han D F, Xu Q H, et al. More Ramapithecus skulls found from Lufeng hominoid site, Yunnan-Report on the excavation of the site in 1981 (in Chinese). Acta Anthropol Sin, 1982, 1: 101-108

11 Wu R K, Xu Q H, Lu Q W. Morphological features of Ramapithecus and Sivapithecus and their phylogenetic relationships-Morphology and comparison of the crania (in Chinese). Acta Anthropol Sin, 1983, 2: $1-10$

$12 \mathrm{Xu}$ Q H, Lu Q W. Lufengpithecus lufengensis-An Early Member of Hominidae (in Chinese). Beijing: Science Press, 2008

13 Zhang X Y, Zheng L, Gao F, et al. A preliminary study of the skull of Ramapithecus unearthed at Hudie Hill of Yuanmou County (in Chinese). J Yunnan Univ (Soc Sci), 1988, 5: 55-61

14 Ho C K. A new Pliocene hominoid skull from Yuanmou, southwest China. Hum Evol, 1990, 5: 309-318

15 Kelley J, Gao F. Juvenile hominoid cranium from the late Miocene of southern China and hominoid diversity in Asia. Proc Natl Acad Sci USA, 2012, 109: 6882-6885

16 Zhang Y P, You Y Z, Ji H X, et al. The Cenozoic deposits of the Yunnan Region (in Chinese). Prof Papers Strat Paleontol, 1978, 7: 1-21

17 Zhu Y M, Zhou L P, Mo D W, et al. A new magnetostratigraphic framework for late Neogene Hipparion Red Clay in the eastern Loess Plateau of China. Palaeogeogr Palaeoclimatol Palaeoecol, 2008, 268: 47-57

18 Flynn L J. The antiquity of Rhizomys and independent acquisition of fossorial traits in subterranean muroids. Bull Am Mus Nat Hist, 2009, 331: $128-156$

19 Tedford R H, Flynn L J, Qiu Z. Yushe Basin, China; Paleomagnetically calibrated mammalian biostratigraphic standard for the Late Neogene of Eastern Asia. J Vert Paleontol, 1991, 11: 519-526

20 Saegusa H, Thasod Y, Ratanasthien B. Notes on Asian stegodontids. Quat Intl, 2005, 126-128: 31-48

21 Wang W W. Correlation of pollen sequences in the Neogene palynofloristic regions of China. Palaeoworld, 2006, 15: 77-99

22 Cande S C, Kent D V. Revised calibration of the geomagnetic polarity timescale for the Late Cretaceous and Cenozoic. J Geophys Res (Solid Earth), 1995, 100: 6093-6095

23 Gradstein F M, Ogg J G, Smith A G. A Geologic Time Scale 2004. Cambridge: Cambridge University Press, 2005

24 Zheng L. New Lufengpithecus hudienensis fossils discovered within the framework of State Key Project of the 9th Five Year Plan (in Chinese). In: Qi G Q, Dong W, eds. Lufengpithecus hudienensis Site. Beijing: Science Press, 2006. 41-73

25 Chaimanee Y, Jolly D, Benammi M, et al. A middle Miocene hominoid from Thailand and orangutan origins. Nature, 2003, 422: 61-65

26 Jaeger J-J, Soe A N, Chavasseau O, et al. First hominoid from the late Miocene of the Irrawaddy Formation (Myanmar). PLoS One, 2011, 6: e17065

27 Cobb S N, O'Higgins P. Hominins do not share a common postnatal facial ontogenetic shape trajectory. J Exp Zool (Mol Dev Evol), 2004, 302B: 302-321

28 Liu W, Zheng L. Comparisons of tooth size and morphology between the late Miocene hominoids from Lufeng and Yuanmou, China, and their implications. Anthropol Sci, 2005, 113: 73-77

29 Ward S C, Brown B. The facial skeleton of Sivapithecus indicus In: Swindler D, Erwin J, eds. Comparative Primate Biology, Vol. 1, Systematics, Evolution, and Anatomy. New York: Alan R. Liss, 1986. 413-452

30 Begun D R, Kordos L. Phyletic affinities and functional convergence in Dryopithecus and other Miocene and living hominoids. In: Begun D R, Ward C V, Rose M D, eds. Function, Phylogeny, and Fossils: Miocene Hominoid Evolution and Adaptations. New York: Plenum, 1997. 291-316

31 Gao F, Kelley J, Zheng L, et al. Juvenile skull of Lufengpithecus from Yuanmou, Yunnan Province, China (in Chinese). In: Yang D C, Yang S X, eds. Collected Works for "The 40th Anniversary of Yuanmou Man Discovery and the International Conference on Palaeoanthropological Studies". Kunming: Yunnan Science and Technology Press, 2006. 40-63

32 Ciochon R L. The mystery ape of Pleistocene Asia. Nature, 2009, 459: 910-911

33 Schoenbohm L M, Burchfiel B C, Chen L Z. Propagation of surface uplift, lower crustal flow, and Cenozoic tectonics of the southeast margin of the Tibetan Plateau. Geology, 2006, 34: 813-816

34 Clark M K, House M A, Royden L H, et al. Late Cenozoic uplift of southeastern Tibet. Geology, 2005, 33: 525-528

35 Jablonski N G, Su D, Kelley J, et al. The Mio-Pliocene monkey, Mesopithecus, in China. Am J Phys Anthropol, Suppl, 2011, S52: 174

36 Dong W, Qi G Q. Hominoid-producing localities and biostratigraphy in Yunnan. In: Wang X M, Flynn L J, Fortelius M, eds. Fossil Mammals of Asia: Neogene Biostratigraphy and Chronology. New York: Columbia University Press, 2013. 293-313

37 Pan Y Y. Primates Linnaeus, 1758 (in Chinese). In: Qi G Q, Dong W, eds. Lufengpithecus hudienensis Site. Beijing: Science Press, 2006. 131-148

Open Access This article is distributed under the terms of the Creative Commons Attribution License which permits any use, distribution, and reproduction in any medium, provided the original author(s) and source are credited. 